\title{
Blades Optimization for Maximum Power Output of Vertical Axis Wind Turbine
}

\author{
Ahmad Adnan Shoukata, Adnan Aslam Noon ${ }^{b}$, Muhammad Anwara, Hafiz Waqar Ahmedc, \\ Talha Irfan Khan ${ }^{a}$, Hasan Koten ${ }^{\mathrm{d}}$, Muftooh Ur Rehman Siddiqie*, Aamer Sharife \\ ${ }^{a}$ Department of Mechanical Engineering, Institute of Space Technology, Islamabad, Pakistan \\ ${ }^{b}$ Department of Mechanical Engineering, International Islamic University, Islamabad, Pakistan \\ 'Department of Mechanical Engineering, Sungkyunkwan University, Republic of South Korea \\ ${ }^{d}$ Department of Mechanical Engineering, Istanbul Medeniyet University, Turkey \\ eDepartment of Mechanical Engineering, CECOS University of IT and Emerging Science, Peshawar, Pakistan
}

\begin{abstract}
Wind power is a significant and urging sustainable power source asset to petroleum derivatives. Wind machines, for example, H-Darrieus vertical pivot wind turbines (VAWTs) have increased much notoriety in research network throughout the most recent couple of decades because of their applications at destinations having moderately low wind speed. Be that as it may, it is noticed that such wind turbines have low effectiveness. The point of this examination is to plan rotor cutting edges which could create most extreme power yield and execution. Different plan factors, for instance, harmony length, pitch edge, rotor distance across, cutting edge length and pitch point are explored to upgrade the presentation of VAWT. Rotor cutting edges are manufactured using the NACA-0030 structure and tried in wind burrow office and contrast its outcomes and DSM 523 profile. Numerical simulations are performed to get best geometry and stream conduct for achieving greatest power. It is seen that for higher tip-speed-proportion (TSR), shorter harmony length and bigger distance across the rotor (i.e., lower robustness) yields higher effectiveness in NACA 0030. Nevertheless, for lower TSR, the more drawn out agreement length and slighter distance across rotor (i.e., higher strength) gives better implementation. The pitch point is $-2^{\circ}$ for TSR $=3$ and $-3^{\circ}$ for TSR $=2.5$. The most extreme power yield of the wind turbine is acquired for the sharp edge profile NACA 0030. Besides, instantaneous control coefficient, power coefficient (CP) is the greatest reason for azimuthal edge of $245^{\circ}$ and least esteem for $180^{\circ}$.
\end{abstract}

Keywords: Design optimization; H-Darrieus VAWT; NACA 0030; DSM 523; Maximum power; TSR; Optimum azimuthal angle.

Article History: Received: $1^{\text {st }}$ January 2021; Revised: $4^{\text {th }}$ March 2021; Accepted: 12 ${ }^{\text {th }}$ March 2021; Available online: $25^{\text {th }}$ March 2021 How to Cite This Article: Shoukat, A.A., Noon, A.A., Anwar, M., Khan, T.I., Koten, H., Siddiqi, M.U.R. and Sharif, A. (2021) Blades Optimization for Maximum Power Output of Vertical Axis Wind Turbine. Int. Journal of Renewable Energy Development, 10(3), 585-595 https://doi.org/10.14710/ijred.2021.35530

\section{Introduction}

Horizontal axis wind turbines and vertical axis wind turbines are two distinct types of wind turbines; VAWT can be preferred for average to trivial power systems owing to its squat price, compacted proposal and malleability for native systems in wind power cohort. Besides, wind direction is not very important for VAWT, so a yaw regulating scheme is not vital and racket level is likewise short than that of HAWT. It is unfortunate fact that vertical axis wind turbines have lesser competence as likened to horizontal axis wind turbines Shahizare et al. (2016). Researchers are trying to improve the turbine blade and flow behavior for the improvement in VAWTs to enhance its performance. Computational fluid dynamics (CFD) has been progressed in couple of years which have led to very accurate model predictions. Several works on the effects of the blade-shape have been showed.

Maître et al. (2005) studied the marine turbine and they recycled unsteady solver to detention the active stall singularities and unsteady rotating properties. Nini et al. (2014) used the moving mesh approach and implemented the Spalart-Allmaras one-equation turbulent model to two blade VAWTs. Lanzafame et al. (2014) conducted the 3-D simulations of the aerodynamic turf around the three bladed VAWT for two values of the TSR, i.e. TSR $=1.53$ and $\mathrm{TSR}=2.6$. The lower velocity standards for $\mathrm{TSR}=1.53$ proposes that in this formation the wind turbine excerpts additional energy. At TSR=2.6, the wake is in regular pattern and offerings lower velocity values. Dynamic stall was experienced if the value of TSR=2.6. Mohamed (2013) numerically and experimentally evaluate performance of small VAWTs by the impact of solidity and hybrid system and investigating torque and power coefficient. The results showed that the rising the turbine solidity improves the Darrieus turbine self-starting capability (Saeed et al. 2017). Under different wind speeds, a computational analysis was performed on the stable and unstable aerodynamics performances of an airborne wind turbine system with an NREL Phase IV rotor. It was

* Corresponding author: muftooh.siddiqi@gmail.com 
reported that in an airborne configuration corresponding to the free stream velocity, the maximum increase in rotor torque is $17 \%$. Furthermore, a strong aerodynamic force causes the shell structure to be highly unstable, reducing wind turbine efficiency. Shen et al. (2016) led a research to see the properties of chord distribution and twisted angle on the recital of non-straight bladed small wind turbine. The results indicates that wind turbine blades with a three-dimensional stacking line have higher efficiency than blade geometries optimised in two dimensions. Moreover, there is literature on the impact of geometrical parameters on VAWT overall performances. Roh et al. (2013) studied the outcomes of mathematical simulations, wherein they explored the result of Reynolds number, solidity and blade profile on the wind turbine performance. The researchers originate that an upsurge in the assessment of solidity from 0.08334 to 0.30 can grow the top value of power coefficient $\left(\mathrm{C}_{\mathrm{P}}\right)$ when the assessed value of solidity will be more amplified from 0.30 to 0.7 for NACA0015 airfoil. Alike approach is also implemented by Maeda et al. (2016) who performed the experiments arranged on the wind tunnel for the straight bladed VAWT to find out the outcome of solidity on varied limits such as lift force, drag coefficients and pressure coefficient, etc. They used two to five bladed of small wind turbine models with NACA 0021 airfoil parts. They discovered that the power output of a wind turbine decreased as the solidity value increased, and a similar trend was found for the torque coefficient.

Claessens (2006) studied the diverse kinds of airfoil, including NACA 0018, 0021, 0012, and 0015, to find out the influence of airfoil wideness over the tip speed ratio and Reynolds number regarding the enactment of Vertical axis Wind Turbines. Fiedler and Tullis (2009) performed the experimentation for an exposed airborne tunnel facility, to note the outcome of pitch angle on vertical axis wind turbine enactment. The prodigious solidity is used for vertical axis wind turbines with NACA0021and NACA0015 as blade shapes, chord length of $0.5 \mathrm{~m}, 2.7 \mathrm{~m}$ rotating diameter and $3.5 \mathrm{~m}$ blade length. The tryouts were performed at four different values of pitch angle $\left(0^{\circ}, \pm 4.8^{\circ}, \pm 8.5^{\circ}\right)$ with a allowed rivulet wind velocity of $12 \mathrm{~m} / \mathrm{s}$. Their examination presented the maximum value of $\mathrm{CP}_{\mathrm{P}}$ which was originate at pitch angle of $-8.5^{\circ}$, at TSR significance value of 1.6 in all four studied cases and contrariwise for pitch angle of $+8.5^{\circ}$. Sabaeifard et al. (2012) researched about the best outline arrangement of vertical axis wind turbines by means of the results of numerical simulations used by different researchers and compared the performance of DUW and NACA 0018 airfoil. In the ongoing past, a few analysts have likewise attempted various arrangements of $\mathrm{H}$-Darrieus wind turbines. Ponta et al. (2007) studied that the power output and overall effectiveness of the design were found to be lower than the conformist scheme, despite the comparatively complex design of a Darrieus rotor plan being compared to conventional straight bladed $\mathrm{H}$ Darrieus rotor mainly due to extraordinary vortex generation and initial flow separations. Ferreira and Geurts (2015) researched about the airfoil shape of lift driven vertical axis wind turbines by means of lift gradient and drag as schematic designed parameters. Since the designed airfoil is lighter, the rotor speed is reduced. The maximum value of $\mathrm{Cp}$ was observed at a pitch angle of $8.5^{\circ}$, with a TSR significance value of 1.6 in all four cases studied, and contrariwise at a pitch angle of $+8.5^{\circ}$, with a TSR significance value of 1.6. Sabaeifard et al. (2012) researched about the best outline arrangement of vertical axis wind turbines by means of the results of numerical simulations used by different researchers and compared the performance of DUW and NACA 0018 airfoil mass and this thing showed the greater aerodynamic performance as well. Table 1 provides the summary of more previous works done by various researchers. Rezaeiha et al. (2017) used computational fluid dynamics (CFD) calculations and investigated the trailing edge and leading edge separation, differences in loads and moments on the turbine, and angle of attack (AOA). It was observed that changes in pitch angle cause instantaneous loads and moments between the turbine's downwind and upwind halves. Wong et al. (2018) performed 3D numerical simulations to characteristics the aerodynamic performance of a straight-bladed NACA0021 VAWT. It was absorbed that the VAWT performance largely dependent on the position of the deflector ,also the coefficient of power $\left(C_{p}\right)$ of the VAWT improved significantly. Elsakka et al. (2019) absorbed accurate method for calculating constantly changing angle of attack at two reference stream point of turbine blades with the help of velocity flow field. The analysis revealed that maintaining more favourable angle of attack (AOAs), lift, and drag distribution improved the turbine's overall efficiency. Posa (2020) studied the tip speed ration (TSR) of a vertical axis wind turbine using a computational approach based on Large-Eddy Simulation (LES). It was absorbed that flow downstream of vertical axis wind turbine to its far wake behavior takes shorter distance at higher value of TSR. Sun et al. (2021) investigated the effect of blade number and offsetting pitching on the efficiency of a vertical axis wind turbine. Further the analysis showed that the blade number and offsetting pitching angle could reduce or delay vortex separation, thereby improving the turbines overall efficiency.

Divakaran et al. (2021) absorbed and compared the aerodynamic performance of helical vertical axis wind turbine (VAWT) with straight blade VAWT using 3D numerical simulations by investigating the effects of the helix angle of the blades. It showed that overall performance and flow interaction of helical VAWT were totally different from those of straight VAWT.

In this study, 2-D numerical analysis has been achieved to design the Darrieus VAWT blade profile to enhance the turbine performance by using various design parameters such as rotor chord length, diameter, and length of the blade and pitch angle for both blade profiles. The results of steady state numerical simulations for these blade profiles are authenticated through the trial records gained through wind tunnel testing. Furthermore, CFD analysis was carried out to determine the critical azimuthal positions for maximum turbine performance. 
Table 1

Rundown of CFD studies utilizing diverse shapes for Darrieus VAWT

\begin{tabular}{|c|c|c|}
\hline Researcher (s) & Blade profile & CFD Turbulence model \\
\hline Zhu et al. (2013) & NACA0018 & 2-D URANS \\
\hline Danao et al. (2012) & NACA0012, 0022, 5522 & 2-D RANS \\
\hline Almohammadi et al. (2013) & NACA0015 & SST and 2-D URANS \\
\hline Elkhoury et al. (2015) & S-809, 9000, 1046, NACA0021, S-1046, & 2-D URANS \\
\hline Danao et al. (2013) & NACA $0018,634-221$ & 3-D LES \\
\hline Wekesa et al. (2014) & NACA0022 & SST and 2-D URANS \\
\hline Wekesa et al. (2015) & NACA0012, 0022 & 2-D URANS \\
\hline Almohammadi et al. (2013) & NACA0022 & SST and 2-D URANS \\
\hline
\end{tabular}

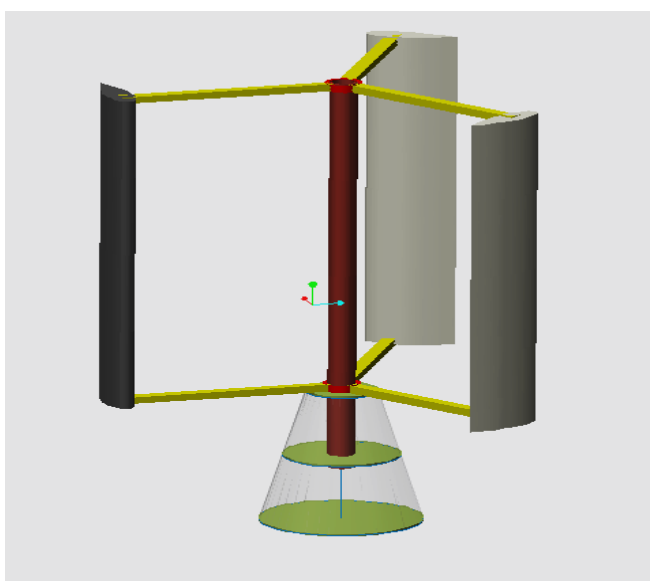

Fig.1. Perspective view of wind turbine

\section{Materials and Methods}

A three bladed H-Darrieus wind turbine was fabricated wind burrow office. The wind turbine has even connecting shafts through a rectangular cross-section, which has the similar angular swiftness and ways as the VAWT. It was presumed that the connecting rod and blades were inflexible thus, they cannot move from their stationary positions during revolution. NACA0030 blade profile was used in the present study and its comparison was through with DSM 523 asymmetric. Modelling of the individual blades has been achieved through PTC Creo® and complete assembly with three straight blades was created according to the guidelines provided in Shahizare et al. (2016). Figure 1 shows the steps involved in generating the $\mathrm{CAD}$ model of the wind turbine.

Tetrahedron shape mesh is utilized in the vast majority of the regions however hexahedron mesh is connected close to the bladed surface for having precise outcomes as appeared in Figure 2. The entire computational area has been partitioned into two sections i.e. stationary and rotating sections. Rotating part moves with respect to the stationary parts to get better reenactment results. A sliding mesh method is used to address the revolving effects of the blades. A frozen rotor type of domain interface was used to connect both domains. The blade profiles for experimentation are as shown in Figure 3. Mesh sensitivity analysis is carried out for five different mesh sizes at TSR values of 1.3 to find the influences of the grid size on the output power values. Extreme value of $C_{P}$ was found to be 0.267 through experiments which changes negligibly for mesh sizes from 5 to 9 million element as shown in Figure 4 for both the bladed profiles, however for DSM 523, the mesh was more confined near the tips of the blade due to curved edges. Therefore, a mesh size of 7 million was used in entire simulations.

The numerical simulations are done to utilize a little time step relating to a $0.1^{\circ}$ augmentation in azimuthal position of rotor, so as to consider exceptionally complex phenomenon, for example, the connection of the wake with rotating fins or blades, and especially, dynamic slow down or stall. Hence to complete the simulations procedure more "easily", and to precisely build up the stream field around the rotor, the rotational speed is directly expanded Lee and Lim (2015). To relate the produced torque with rotor rotational speed, the wind speed at the bay BC is stable at an on-structure or designed value and moreover to acquire a basic connection between the tip speed ratio (TSR) and the power coefficient(Cp). For inclinations, a least-squares cell-based algorithm is embraced, while so as to solve the equations to identify with pressure, turbulence, momentum and energy, the second order upwind spatial discretization calculation is utilized while performing the simulations. The augmentation in the azimuthal position $(\mathrm{d} \theta)$ is kept as low as $0.11^{\circ}$ for the counts of insecure or unsteady recreations. The intensity of turbulence in the up and coming free stream wind at the channel $\mathrm{BC}$ of the 
Citation: Shoukat, A.A., Noon, A.A., Anwar, M., Khan, T.I., Koten, H., Siddiqi, M.U.R. and Sharif, A. (2021) Blades Optimization for Maximum Power Output of Vertical Axis Wind Turbine. Int. Journal of Renewable Energy Development, 10(3), 585-595, doi: 10.14710/ijred.2021.35530

$\mathrm{P}$ a g e $\mid 588$

space is $5 \%$. Navier-Stokes equations are discretized by means of finite-volume technique. The mean and fluctuating components of air flow properties are relieved into the standard Navier-Stokes equations, which provide the URANS equations as follows:

$\frac{\partial \overline{u_{m}}}{\partial x_{m}}=0$ $\frac{\partial \overline{u_{m}}}{\partial t}+\overline{u_{n}} \frac{\partial \bar{u}_{m}}{\partial x_{n}}=-\frac{1}{\rho} \frac{\overline{\partial p}}{\partial x_{m}}+v \frac{\partial^{2} \overline{u_{m}}}{\partial x_{n}^{2}}-\overline{u_{n}^{\prime} \frac{\partial u_{m}^{\prime}}{\partial x_{n}}}+\emptyset$

Where,

$\overline{u_{m}} \quad=$ mean velocity in $\mathrm{x}$ direction, $\mathrm{m} / \mathrm{s}$

$\overline{u_{n}} \quad=$ fluctuating velocity, $\mathrm{m} / \mathrm{s}$

$p \quad=$ regular pressure, $\mathrm{Pa}$

$\rho \quad=$ air density, $\mathrm{kg} / \mathrm{m}^{3}$

$v \quad=$ kinematic viscosity, $\mathrm{m}^{2} / \mathrm{s}$.

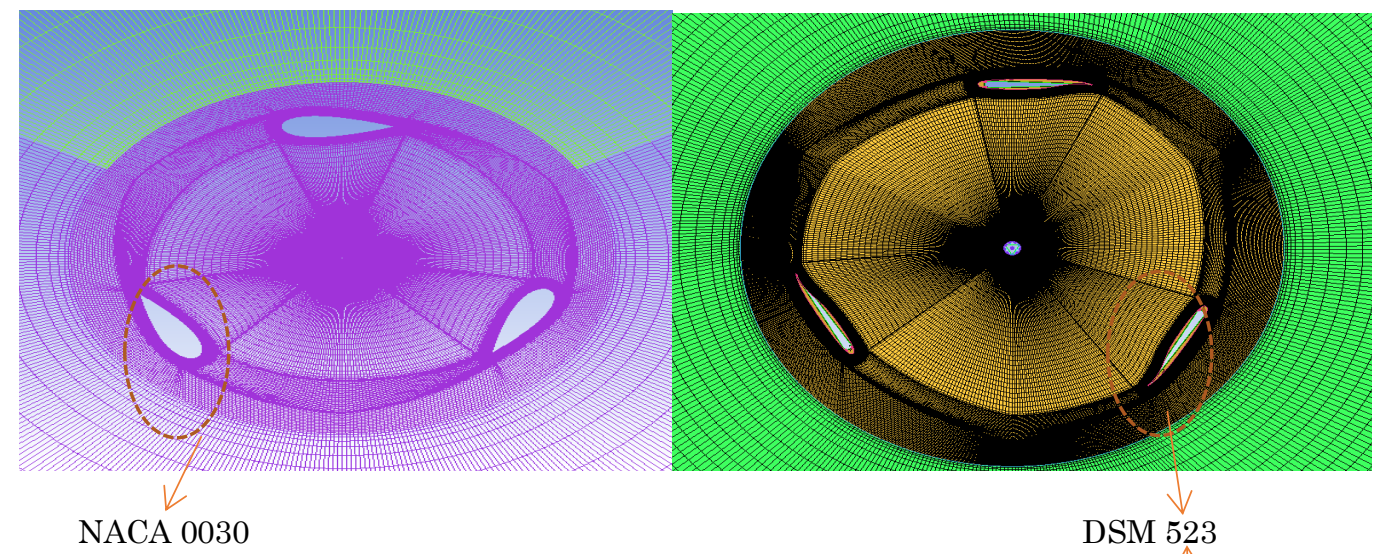

Fig.2. Mesh around the blades

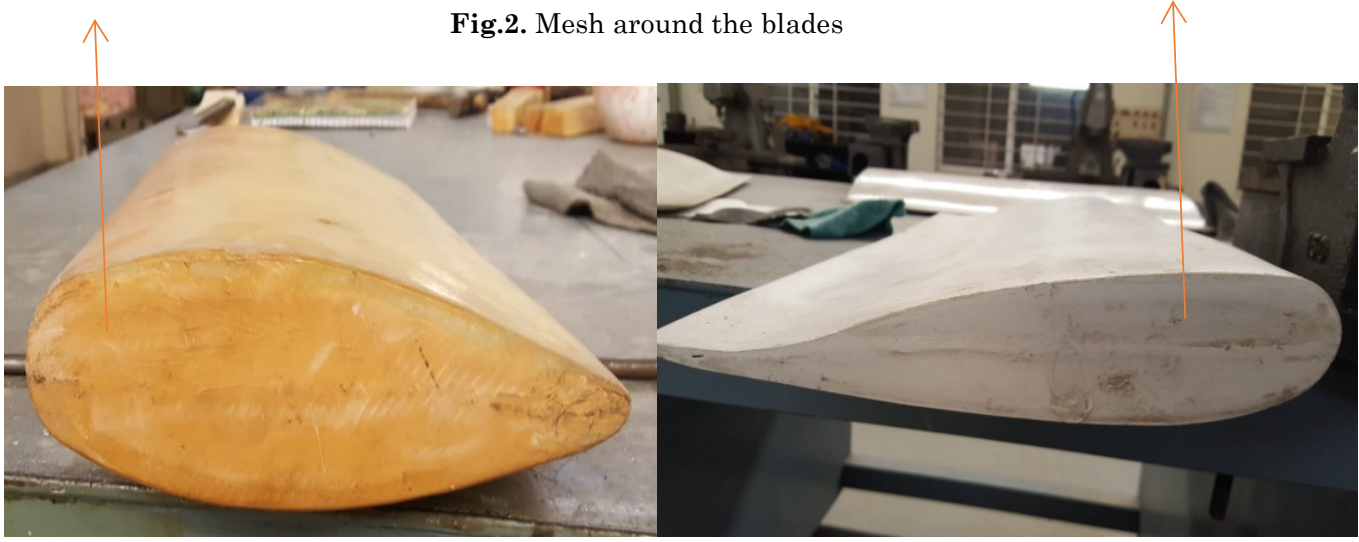

Fig.3. Blade profiles for Experimentation

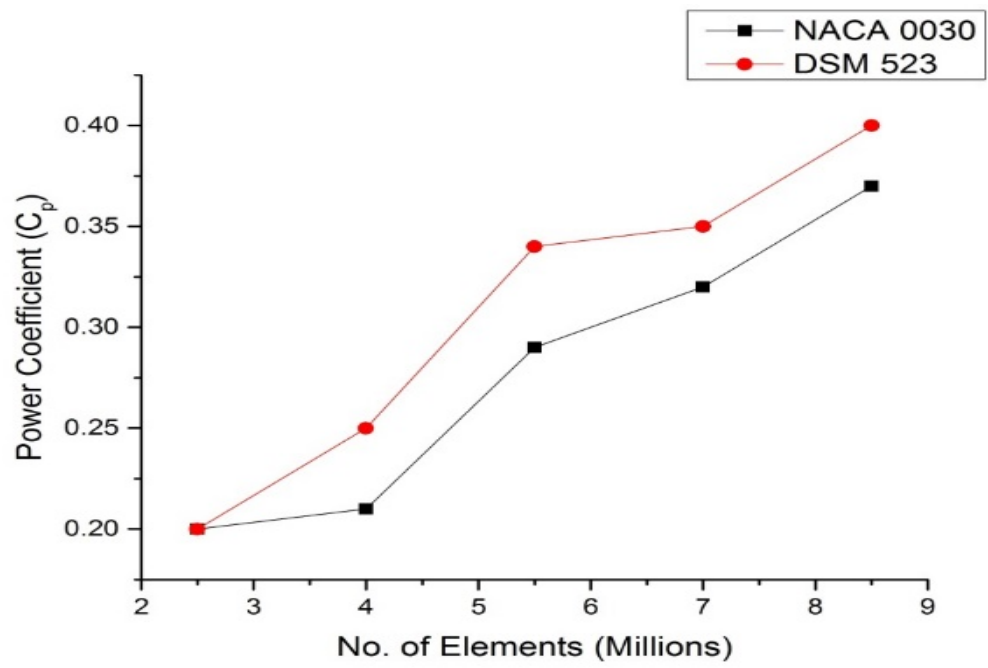

Fig. 4. Mesh sensitivity analysis at TSR $=1.3$ 
Table 2.

RNG k- $\varepsilon$ turbulence model coefficients

\begin{tabular}{cc}
\hline Coefficients & Value \\
\hline $\mathrm{C}_{1 \varepsilon}$ & 1.412 \\
$\mathrm{C}_{2 \varepsilon}$ & 1.678 \\
$\mathrm{C}_{\mu}$ & 0.0854 \\
\hline
\end{tabular}

Table 3

Boundary conditions

\begin{tabular}{ccc}
\hline Location & Type & Value \\
\hline Inlet & Velocity & $6.3 \mathrm{~m} / \mathrm{s}$ \\
Outlet & Pressure & $0 \mathrm{~Pa}$ \\
\hline
\end{tabular}

These terms should be modeled to address the variances connected with turbulence and to numerically close the hoop Bianchini et al. (2016). Body forces such as gravity forces and centrifugal are signified by the term $\emptyset$ and are ignored throughout the computation. The decision of the turbulence model is essential to accomplish the righteous numerical outcomes. The RNG k- $\varepsilon$ turbulence model Li et al. (2016) is chosen which is very appropriate for the forecast of enormous stream separations. The coefficients engaged with the RNG $\mathrm{k}-\varepsilon$ disturbance model is utilized by CFX are appeared in Table 2 . The turbulent tackiness was intended by using the following equation (3).

$\mu_{t}=\rho C_{\mu} \frac{k^{2}}{\epsilon}$

Where, $\rho$ is fluid density, $C_{\mu}$ is a constant having value of $0.00845, k$ is turbulent kinetic energy and $\epsilon$ is turbulent dissipation. Uniform speed is connected at the channel and weight at the outlet as the limit conditions as appeared in Table 3. No-slip condition is compulsory along the edges, top, and base surfaces of the CFD domain. To separate the moving and fixed parts of the domain, two different regions are selected. The connection between these two regions is made by domain interface of frozen rotor type.

Wind turbine model is placed at a distance of $6 \mathrm{D}$ downstream from the inlet $\mathrm{BC}$ and $8 \mathrm{D}$ upstream from the outlet $\mathrm{BC}$; where $\mathrm{D}$ is the rotational diameter of the reference wind turbine. Similarly, dimensions of both sides of the CFD domain are similar to that of wind tunnel $(2 \mathrm{~m} \times 2 \mathrm{~m})$. Different non-dimensional parameters like TSR, Solidity, torque coefficient power coefficient are also determining to evaluate the performance of the wind turbine.

\section{Results and Discussion}

To investigate the designed wind turbine, it is placed in front of large scale wind tunnel which has been setup the wind speeds up to $10 \sim 15 \mathrm{~m} / \mathrm{s}$ and dimensions of the wind tunnel are $2 \mathrm{~m} \times 2 \mathrm{~m} \times 15 \mathrm{~m}(\mathrm{~W} \times \mathrm{H} \times \mathrm{L})$. Wind speed is observed by using anemometer which was connected $5 \mathrm{~m}$ ahead and at the central stature of the test expedient of the wind turbine. The wind generated energies and rotates the blades. Afterwards, a tachometer is used to measure the amount of rotation by a data logger. The numbers of revolutions are measured through a brake scheme when the anticipated speed is grasped. Torque meter is used to get or find out the blade power. In this research, the angular speed and torque for shaft of wind turbine are measured experimentally by tachometer and a torque sensor respectively. The VAWT performance curve obtained by experimental measurements as well as numerical values is parabolic in shape as shown in Figure 5 and 6 respectively. Graph indicates that maximum power is attained in the TSR range of 1.0-1.4 for both the profiles. In this range, the power coefficient comes out to be around 0.260 for NACA 0030 and 0.33 for DSM 523 bladed profile.

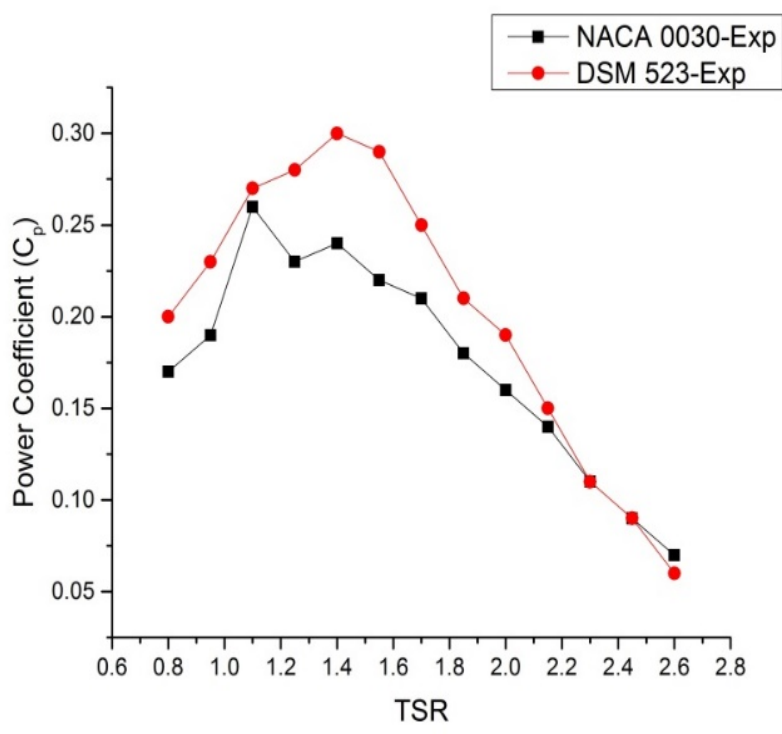

Fig. 5. Comparison between experimental results

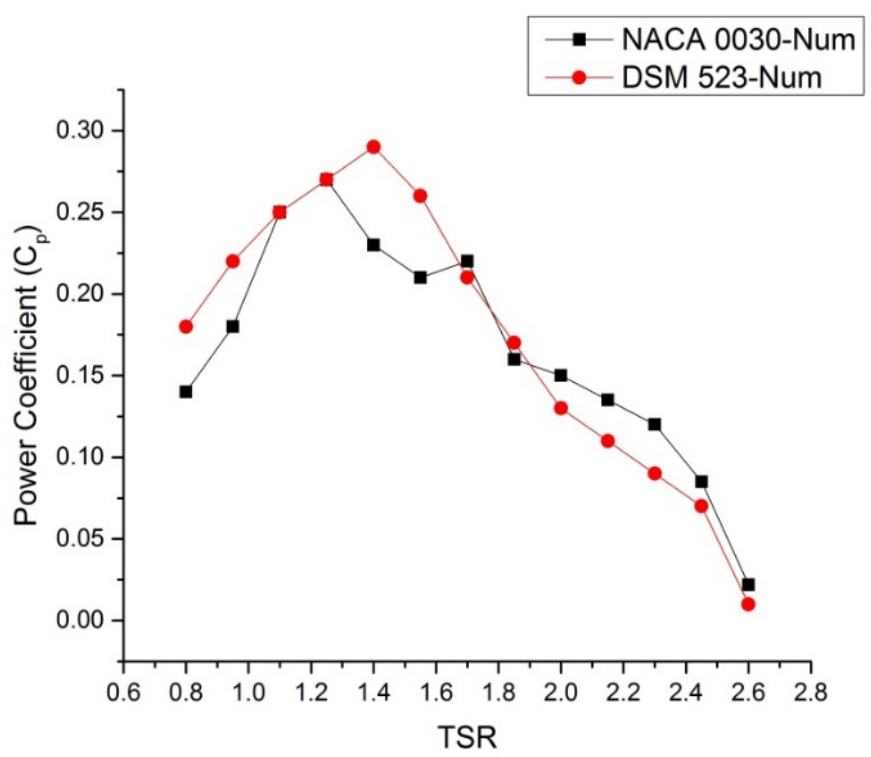

Fig. 6. Comparison between numerical results 
CFD results gives the analogies with the investigational results as Q. Lee (Li et al. 2016) did for HAWT, the regular standard deviation was found to be about $6.90 \%$ for the designed VAWTs. It shows that an optimum design can be achieved by using CFD technique developed in this study, when Darrieus VAWT parameters are altered. The experimental data may contain variable magnitude of uncertainty. Thus, error analysis is performed for all experimental records in order to ensure the correct use of methodology. The overall error may contain two types i.e. precision error and bias error. To estimate the precision error, the standard deviation (SD) is evaluated using equation 4. By careful usage of measurement tools the bias error can be reduced. The total experimental inaccuracy in current case was found to be approximately less than $12 \%$ for designed VAWT based on NACA 0030 blades and almost $15 \%$ for DSM 523 profiles.

$\mathrm{SD}=\sqrt{\frac{\sum_{i=1}^{n}\left(x_{i}-x_{\text {ave }}\right)^{2}}{n-1}}$
Where, $\mathrm{n}$ is the total number of data in a specific series, $x_{i}$ is the $i_{\text {th }}$ value and $x_{\text {ave }}$ is the mean value of that data series. For the performance evaluation of different parameters, a constant rotor diameter of $1200 \mathrm{~mm}$, torque and power coefficients for both profiles as a function of TSR are plotted as shown in Figure $7 \mathrm{a}$ and $7 \mathrm{~b}$ and Figure $8 \mathrm{a}$ and $\mathrm{b}$ respectively. Five dissimilar values of chord lengths: 140, 160, 180, 220, and $280 \mathrm{~mm}$ remain used for both the blade profile (NACA 0030 and DSM 523) and their result can be seen by the graphs shown in Figure 9a and $9 \mathrm{~b}$.

The rotor having the chord length of $140 \mathrm{~mm}$ yields the maximum value of power coefficient when TSR is 2.8 or greater; whereas same is the case for chord length of $280 \mathrm{~mm}$ below TSR value of 2.4. On the other hand, rotor with chord length of $280 \mathrm{~mm}$ shows superior performance in terms of torque coefficient. It shows that in case of lift, the longer chord length rotor gives higher power generation. However, when drag is considered important the longer chord length rotors shows a low performance due to higher air resistance.

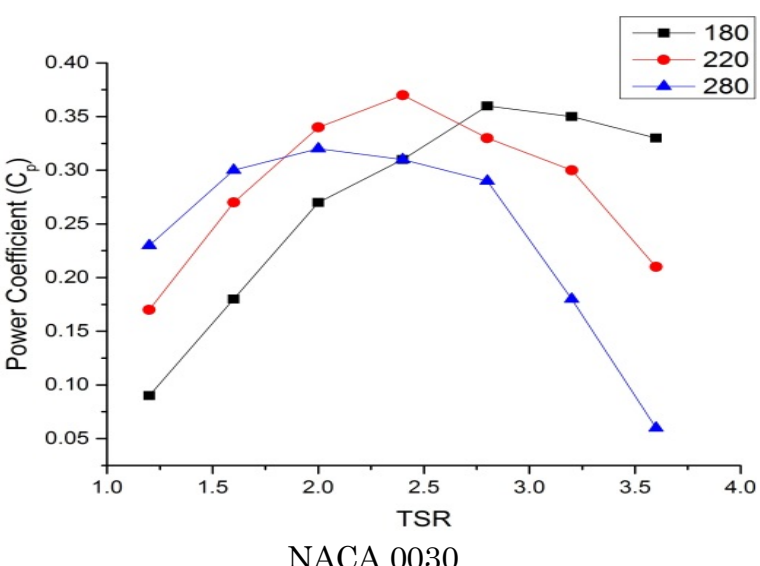

NACA 0030

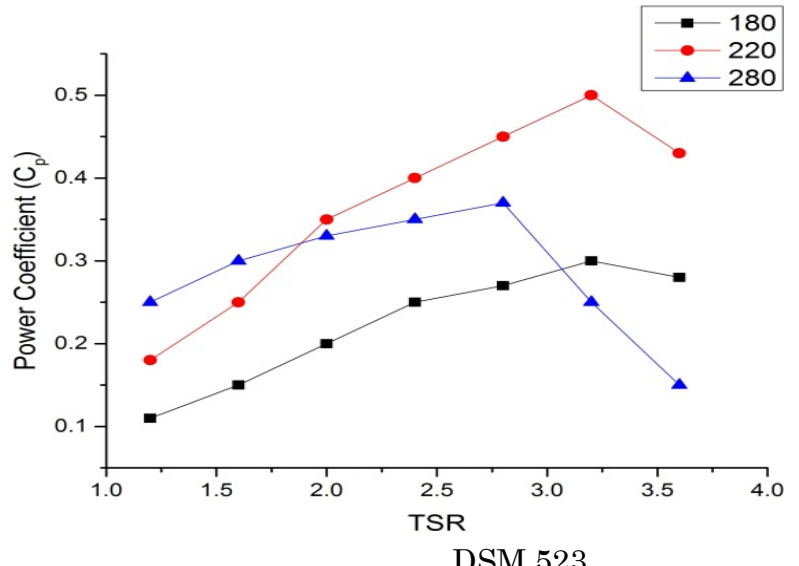

(b)

Fig. 7(a) Effect of Chord Length with Power Coefficient for NACA 0030, (b) Effect of Chord Length with Power Coefficient for DSM 523

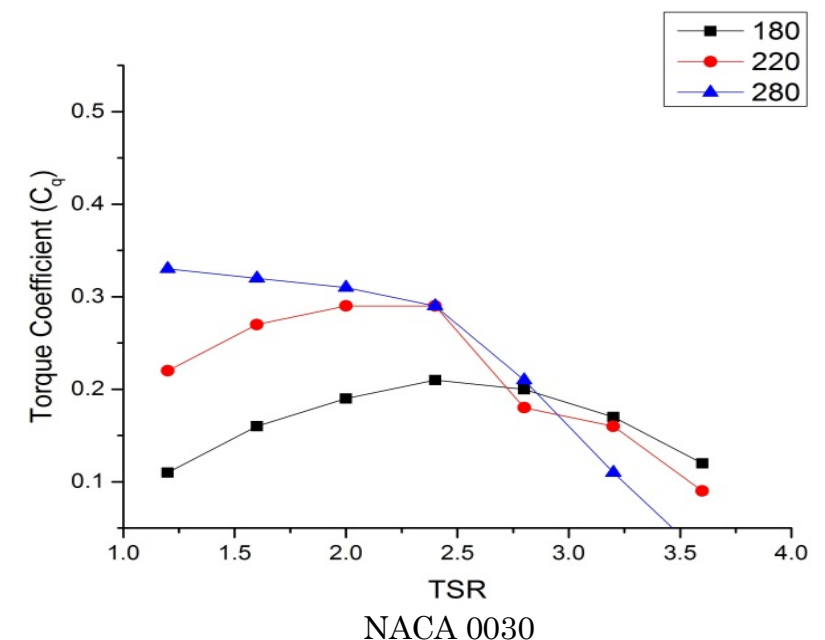

(a)

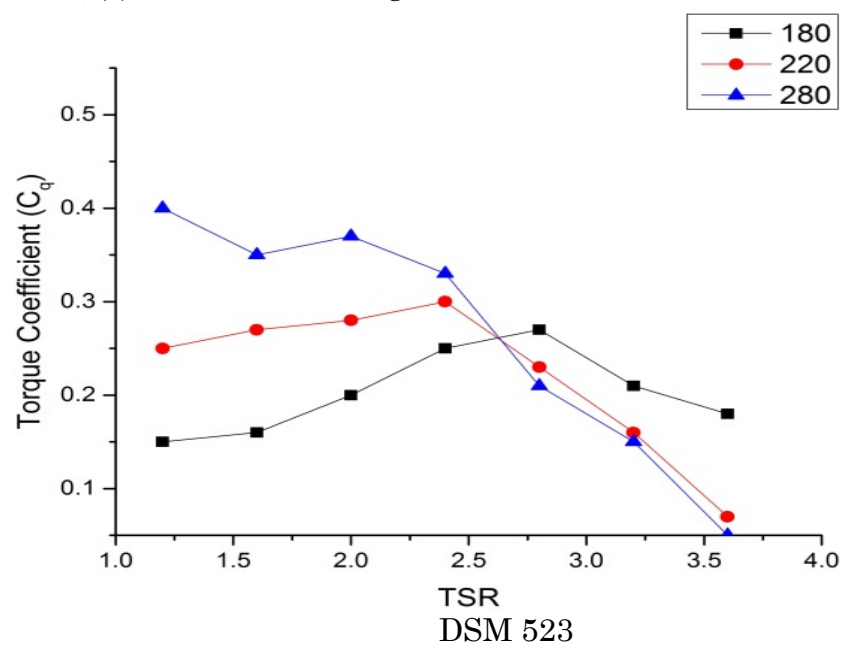

(b)

Fig. 8(a) Effect of Chord Length with Torque Coefficient for NACA 0030, (b) Effect of Chord Length with Torque Coefficient for DSM 523 


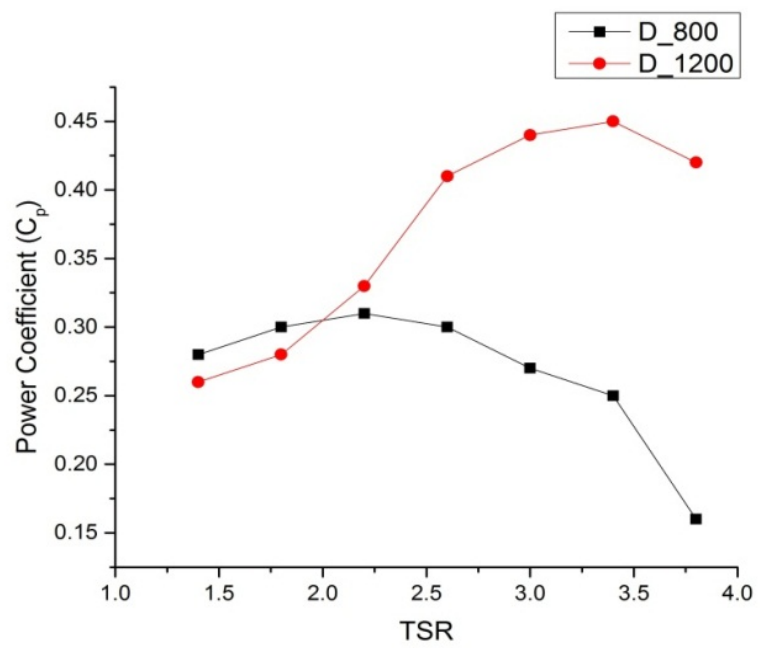

(a)

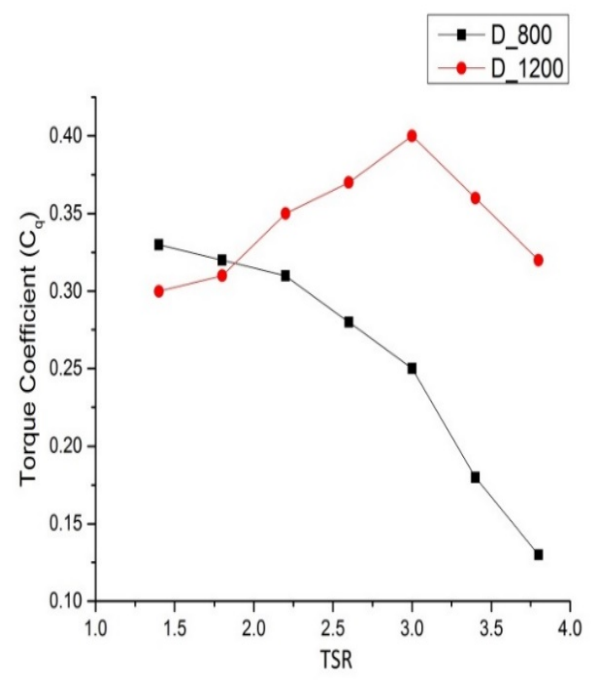

(b)

Fig. 9(a) Effect of runner diameter on Power Coefficient, (b) Effect of runner diameter on Torque Coefficient
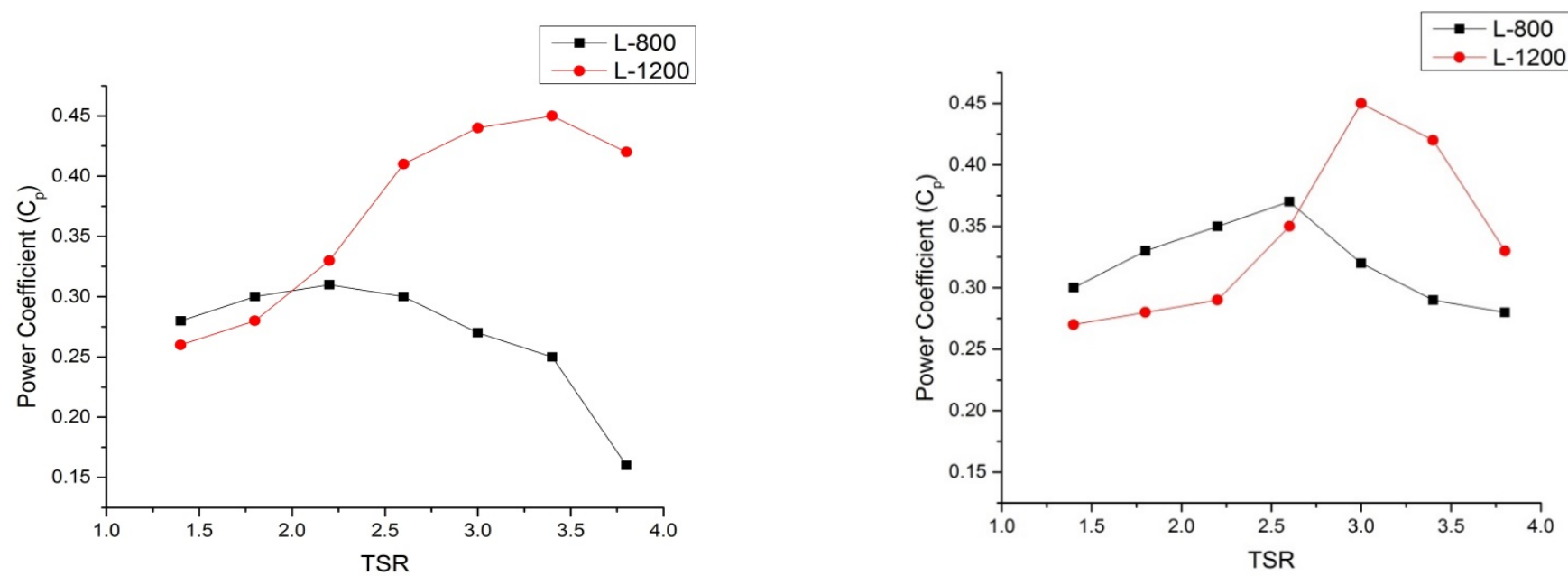

Fig. 10(a) Effect of blade length with Power Coefficient for NACA-0030, (b) Effect of blade length with Torque Coefficient for DSM-523t

In the case of TSR above 1.6, the rotor with $\mathrm{D}=1200 \mathrm{~mm}$ $(\sigma=0.5)$ is more efficient because the torque applied to the rotor shaft increases as the rotor diameter increases. However, when TSR value is lower than 1.6, the rotor with $\mathrm{D}=1000 \mathrm{~mm}(\sigma=0.6)$ yields higher efficiency. Figure $10 \mathrm{a}$ and $10 \mathrm{~b}$ and Figure $11 \mathrm{a}$ and $11 \mathrm{~b}$ show power and torque coefficients versus TSR at constant diameter of $1200 \mathrm{~mm}$. A maximum torque and power coefficients are attained when TSR is larger than 2.2 for $1200 \mathrm{~mm}$ blade length rotor; however, when TSR is less than 2.2, the rotor with blade length of $800 \mathrm{~mm}$ shows the maximum power coefficient. The results demonstration that bigger runner yields great power generation in the situation of lift. However, the taller runner gives lower values when the drag is considered important in DSM 523 profile as it is an asymmetric blade profile and it encounters higher resistance.

Figures $12-15$ shows the static pressure, velocity and vorticity contours binary unlike azimuthal positions, where maximum and minimum standards of $C_{p}$ happened, throughout one thorough rotation of the propeller. In all these figures blade encircled is blade number 1. From Figure 12, the pressure contour around the vertical axis wind turbine blade shows that when the wind turbine is offset upward or downward from the channel's centre line, the pressure difference on the blade is greatly altered compared to when the wind turbine is located at the channel's centerline. Moreover, the Figure 12 shows that at maximum $C_{p}\left(\theta=240^{\circ}\right)$ the pressure contour is at centre while at minimum $C_{p}$ the pressure contour is at edges of the blades. Figure 13 shows that the velocity contour at maximum $C_{p} \quad\left(\theta=240^{\circ}\right)$ and minimum $C_{p}\left(\theta=180^{\circ}\right)$ in which the velocity contour (blue colour) is more widely disturbed than that of minimum $C_{p}\left(\theta=180^{\circ}\right)$. The effect of velocity vectors of (DSM 523) at maximum $C_{p}\left(\theta=240^{\circ}\right)$ shows that at maximum $C_{p}$ the blades of the vertical axis wind turbine face greater wind.

From Figure 15, it is clear that static pressure is maximum at that surface of rotor which is directly facing 
Citation: Shoukat, A.A., Noon, A.A., Anwar, M., Khan, T.I., Koten, H., Siddiqi, M.U.R. and Sharif, A. (2021) Blades Optimization for Maximum Power Output of Vertical Axis Wind Turbine. Int. Journal of Renewable Energy Development, 10(3), 585-595, doi: 10.14710/ijred.2021.35530

$\mathrm{P}$ a g e $\mid 592$

the wind. Hence moving air transfers its momentum to blade 2 , which then tries to accelerate and an increase in speed of blade 2 is observed as shown in Figure 15. The upsurge in linear velocity of blade 2 leads to increase the rotational speed of rotor and finally overall power output is enhanced. Analogous pattern is repeated, whenever any of the three blades approaches directly in front of wind.

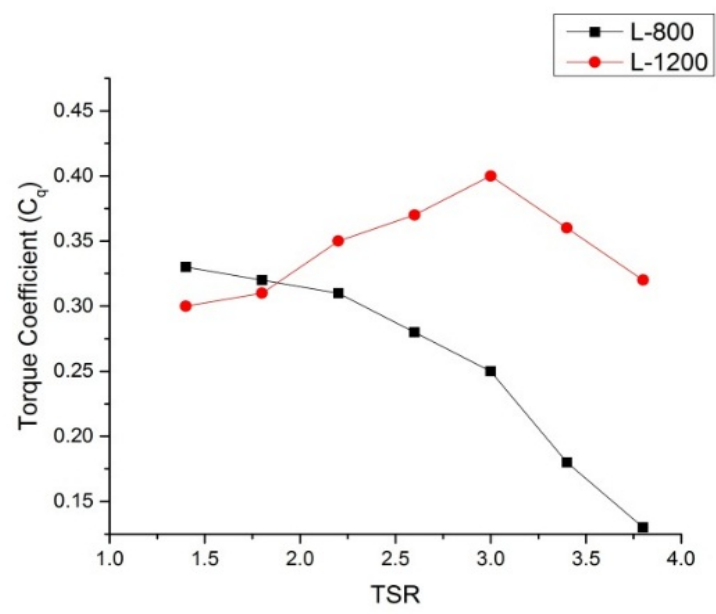

(a)

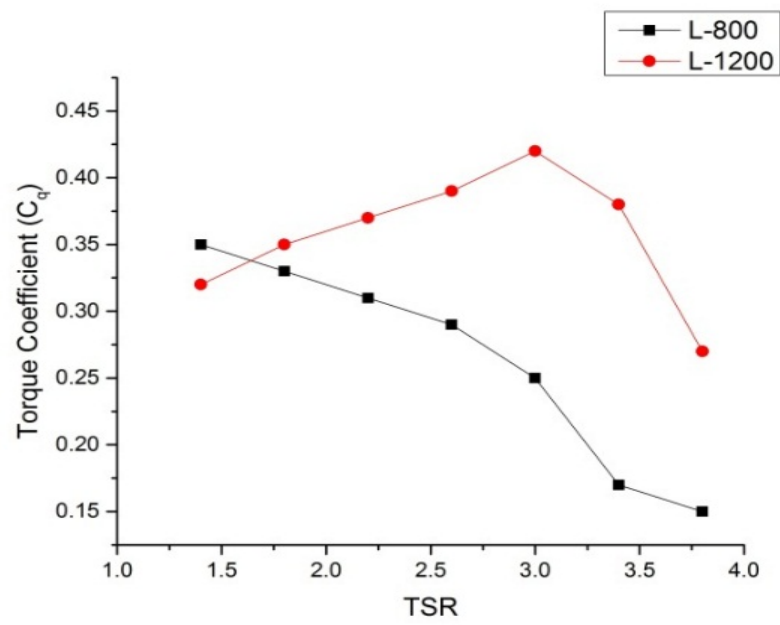

(b)

Fig. 11(a) Effect of blade length with Torque Coefficient for NACA-0030, (b) Effect of blade length with Torque Coefficient for DSM-523

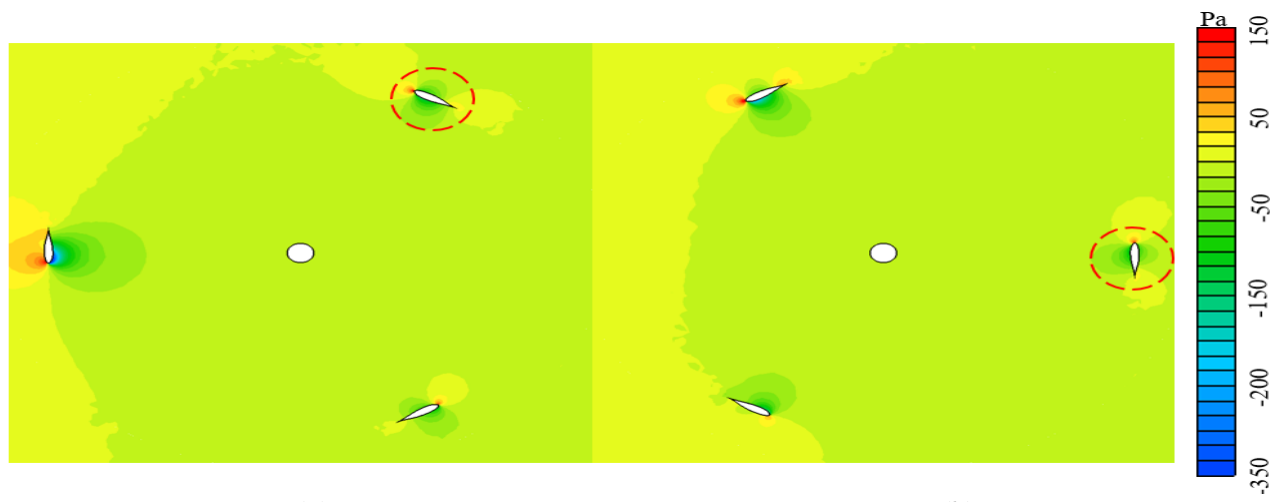

(a) (b)

Fig. 12. Pressure contours (NACA 0030) (a) Max. $C_{p}\left(\theta=240^{\circ}\right)$ (b) Min. $C_{p}\left(\theta=180^{\circ}\right)$

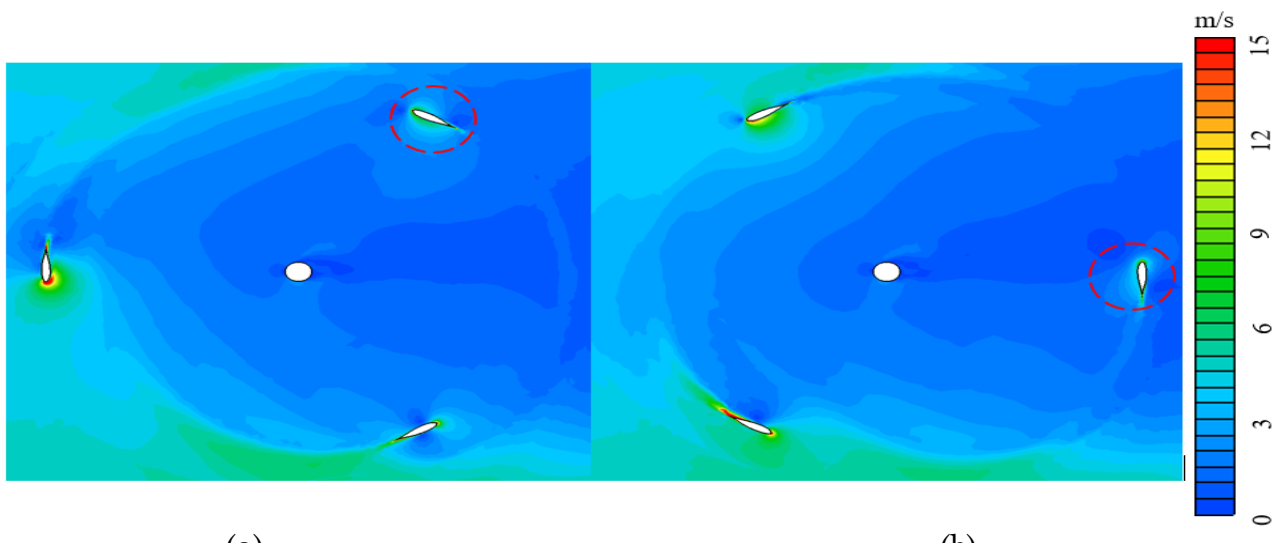

(a)

(b)

Fig. 13. Velocity contours (NACA 0030) (a) Max. $C_{p}\left(\theta=240^{\circ}\right)$, (b) Min. $C_{p}\left(\theta=180^{\circ}\right)$ 


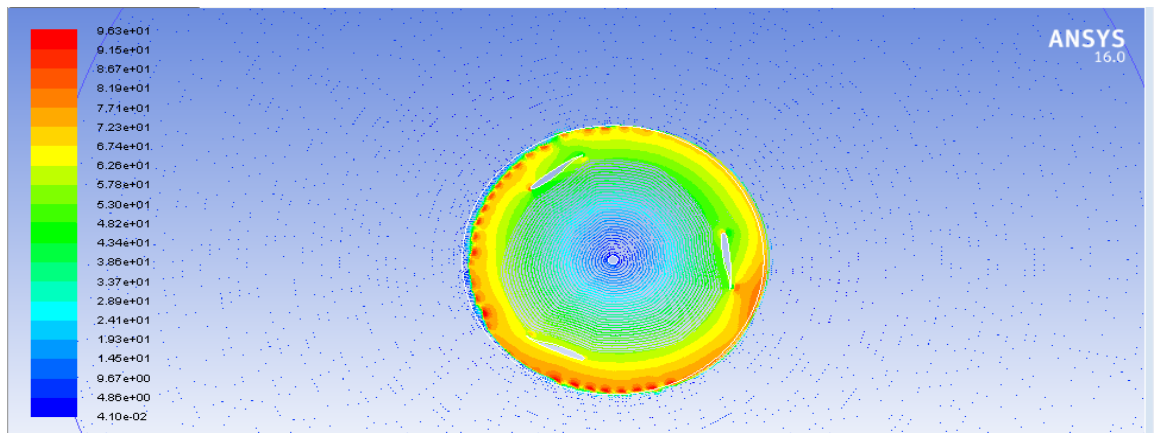

Fig. 14. Velocity (vectors) (DSM 523) (a) Max. $C_{p}\left(\theta=240^{\circ}\right)$

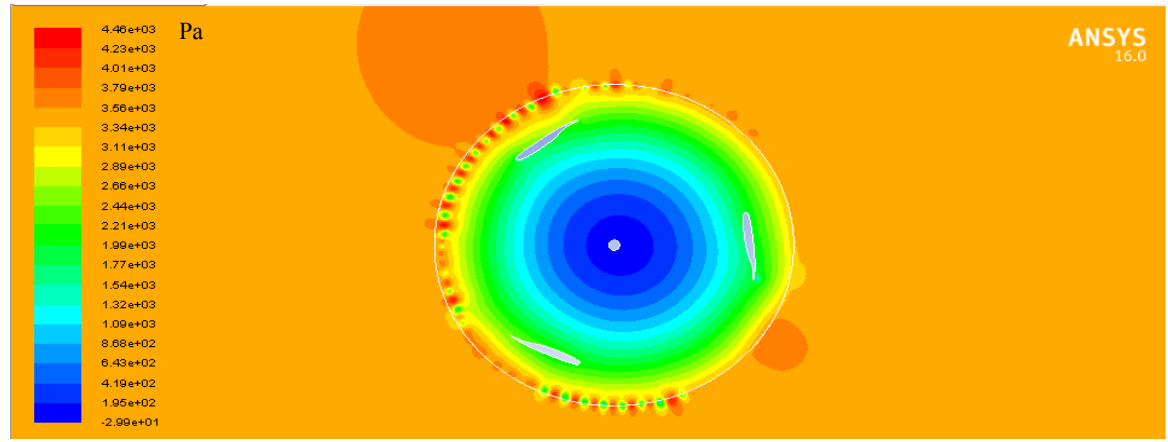

Fig. 15. Pressure contours (DSM 523) Max. $C_{p}\left(\theta=240^{\circ}\right)$

Table $4 \mathrm{a}$ and Table $4 \mathrm{~b}$ provide the overall summary of the suggested values for best results regarding the performance of H-Darrieus VAWT for all the design variables considered in the current study. The suggested value of all the design variables along with $\mathrm{Cp}$ max and TSR for maximum power coefficient are shown in Table 4a. The suggested value of chord length $(\mathrm{mm})$ is $140 \mathrm{~mm}$ and their $\mathrm{Cp}$ max value is 0.40 and 2.8. Table 4 a shows that a maximum power coefficient can be achieved for vertical axis wind turbine with rotor diameter of $1200 \mathrm{~mm}$ and their $\mathrm{Cp}$ max value is 0.46 and TSR value is 2.8 . Moreover, with the effect of chord length on maximum power coefficient of vertical axis wind turbine, the blade length has significant effect on obtaining maximum power. The vertical axis wind turbine will perform best on $1200 \mathrm{~mm}$ blade length along with $\mathrm{Cp}$ max of 0.45 and TSR value of 3.2. In addition to this, the pitch angle and azimuthal position both have high effects on obtaining maximum power coefficient from vertical axis wind turbine. When the azimuthal position become in upstream region, the blade pitch angle become low and when azimuthal position in downstream region, the blade pitch become maximum. Table 4a shows that the azimuthal position is in upstream region due to which the value of pitch angle becomes negative. The value of TSR also effects on power coefficient of vertical axis wind turbine.

Table $4 \mathrm{~b}$ shows that all the design variables have high effect on obtaining maximum power coefficient. The vertical axis wind turbine with the chord length $(280 \mathrm{~mm})$, rotor diameter $(700 \mathrm{~mm})$ and blade length $(1200 \mathrm{~mm})$ obtained maximum torque coefficient. The $\mathrm{C}_{\mathrm{T}} \max$ for chord length, rotor diameter and blade length are 0.32 , 0.38 , and 0.41 respectively. In addition to this, the value of TSR shows that all the design variables results maximum power torque. When the TSR value reaches to 2.0, the blade become more stable and appears to have maximum power coefficient. Therefore, optimum TSR value is needed to obtain maximum torque coefficient.

Table 4a

Optimized results for maximum power coefficient

\begin{tabular}{cccc}
\hline Design variable & Suggested value & C 1 _max & TSR \\
\hline Chord length $[\mathrm{mm}]$ & 140 & 0.40 & 2.8 \\
Rotor diameter [mm] & 1200 & 0.46 & 2.8 \\
Blade length [mm] & 1200 & 0.45 & 3.2 \\
Pitch angle $\left[^{\circ}\right]$ & -2 & 0.35 & 3.0 \\
Azimuthal position $\left[^{\circ}\right]$ & 240 & 0.38 & 2.5 \\
\hline
\end{tabular}


Table 4b

Summary of optimization results for maximum torque coefficient

\begin{tabular}{cccc} 
Design variable & Suggested value & C $_{\text {T_max }}$ & TSR \\
\hline Chord length $[\mathrm{mm}]$ & 280 & 0.32 & 2.0 \\
Rotor diameter $[\mathrm{mm}]$ & 700 & 0.38 & 2.0 \\
Blade length $[\mathrm{mm}]$ & 1200 & 0.41 & 2.8 \\
\hline
\end{tabular}

\section{Conclusions}

In the present study, experimental and 2-D numerical analyses have been performed using NACA0030 blade profile for H-Darrieus VAWT. The finest improved blade profile is anticipated by changing the values of design constraints for extreme power output.

The rotor with chord length $220 \mathrm{~mm}$ gives higher efficiency at TSR 2.5 or less, however $140 \mathrm{~mm}$ chord length rotor yields higher efficiency for TSR 2.5 or more in DSM 523 profile. Hence after comparison with both the blade profiles it is suggested that for maximum power output DSM 523 blade profile should be used. In the range of TSR 2 to 3.5 , the rotor with $\mathrm{D}=1200 \mathrm{~mm}$ is extra resourceful. Whereas, when TSR less is than 2 , the rotor with $\mathrm{D}=1000$ $\mathrm{mm}$ yields higher efficiency.

Maximum torque and power coefficients are achieved when TSR is larger than 2.2 for $1200 \mathrm{~mm}$ blade length rotor, however, once TSR is less than 2.2 , the rotor through blade lengths of 800 and $1000 \mathrm{~mm}$ illustrations the maximum torque and power coefficients. The power coefficient shows a parabolic curve behavior against pitch angle. Maximum power coefficient is achieved at a pitch angle of $-2^{\circ}$ for $\mathrm{TSR}=3$ and $-3^{\circ}$ for $\mathrm{TSR}=2.5$.

Power coefficient in contradiction of azimuthal angle indicates three indigenous maximum and also three indigenous minimum, throughout one ample revolution of propeller; with global maxima of $\mathrm{C}_{\mathrm{p}}$ arises at $245^{\circ}$ and global minima arises at $180^{\circ}$.

\section{References}

Almohammadi, K., Ingham, D., Ma, L. and Pourkashan, M. (2013). Computational fluid dynamics (CFD) mesh independency techniques for a straight blade vertical axis wind turbine. Energy 58, 483-493.

Almohammadi, K., Ingham, D., Ma, L, and Pourkashanian, M (2013). Effect of transitional turbulence modelling on a straight blade vertical Axis wind turbine. Alternative energies, 93-112.

Bianchini, A., Balduzzi, F, Ferrara, G, Ferrari, L.(2016). A computational procedure to define the incidence angle on airfoils rotating around an axis orthogonal to flow direction. Energy conversion and Management 126, 790-798.

Claessens, M. (2006). The design and testing of airfoils for application in small vertical axis wind turbines. MSc thesis TU Delft Netherlands

Danao, L.A., Eboibi, O. and Howell, R. (2013). An experimental investigation into the influence of unsteady wind on the performance of a vertical axis wind turbine. Applied Energy 107, 403-411.

Danao, L.A., Qin, N., Howell, R.(2012). A numerical study of blade thickness and camber effects on vertical axis wind turbines. Part A: Journal of Power and Energy, 226(7), 867-881.
Divakaran, U., Ramesh, A., Mohammad, A and Velamati, R.K (2021). Effect of helix angle on the performance of Helical Vertical axis wind turbine. Energies 14(2), 393.

Elkhoury, M., Kiwata, T., Aoun, E. (2015). Experimental and numerical investigation of a three-dimensional vertical-axis wind turbine with variable-pitch. Journal of Wind Engineering and Industrial Aerodynamics 139, 111-123.

Elsakka, M.M., Ingham, D.B., Ma, L and Pourkashanian, M (2019). CFD analysis of the angle of attack for a vertical axis wind turbine blade. Energy Conversion and Management 182, 154-165.

Ferreira, S.C and Geurts, B. (2015). Aerofoil optimization for vertical-axis wind turbines. Wind Energy 18(8), 1371-1385.

Fiedler, J.A and Tullis, S. (2009). Blade offset and pitch effects on a high solidity vertical axis wind turbine. Wind Engineering 33(3), 237-246.

Lanzafame, R., Mauro, S. and Messina, M. (2014). 2D CFD modeling of $\mathrm{H}$-Darrieus wind turbines using a transition turbulence model. Energy Procedia 45, 131-140.

Lee, Y.-T. and Lim, H.C.(2015). Numerical study of the aerodynamic performance of a 500 W Darrieus-type vertical-axis wind turbine. Renewable Energy 83, 407-415.

Li, C., Zhu, S, Xu,Y.I and Xiao, Y.(2013). 2.5 D large eddy simulation of vertical axis wind turbine in consideration of high angle of attack flow. Renewable Energy 51, 317-330.

Li, Q., Murata, J, Endo, M, Maeda, T and Kamada, Y. (2016). Experimental and numerical investigation of the effect of turbulent inflow on a Horizontal Axis Wind Turbine (Part I: Power performance). Energy 113, 713-722.

Maeda, T., Kamada,Y, Murata, J, K. Shimizu, K., Ogasawara, T, Nakai, A., and Kasuya, T. (2016). Effect of solidity on aerodynamic forces around straight-bladed vertical axis wind turbine by wind tunnel experiments (depending on number of blades). Renewable Energy 96, 928-939.

Maître, T., Achard, J.L, Guittet, L and Ploesteanu, C (2005). Marine turbine development: numerical and experimental investigations. In Workshop on Vortex Dominated Flows. Achievement and Open Problems. Timisoara, Romania.

Mohamed, M. H. (2013). Impacts of solidity and hybrid system in small wind turbines performance. Energy 57, 495-504.

Nini, M., Motta, V., Bindolino, G., Guardone, A.(2014). Threedimensional simulation of a complete vertical axis wind turbine using overlapping grids. Journal of Computational and Applied Mathematics 270, 78-87.

Ponta, F., Seminara, J. and Otero, A. (2007). On the aerodynamics of variable-geometry oval-trajectory Darrieus wind turbines. Renewable Energy 32(1), 35-56.

Posa, A. (2020). Influence of tip speed ratio on wake features of a vertical axis wind turbine. Journal of Wind Engineering and Industrial Aerodynamics 197, 104076.

Rezaeiha, A., Kalkman, I. and Blocken, B. (2017). Effect of pitch angle on power performance and aerodynamics of a vertical axis wind turbine. Applied energy 197, 132-150.

Roh, S.-C., Kang, S.H. (2013). Effects of a blade profile, the Reynolds number, and the solidity on the performance of a straight bladed vertical axis wind turbine. Journal of Mechanical Science and Technology 27(11), 3299-3307.

Sabaeifard, P., Razzaghi, H and Forouzandeh, A (2012). Determination of vertical axis wind turbines optimal 
configuration through CFD simulations. International Conference on Future Environment and Energy.Singapore

Saeed, M., Kim.M.H. (2017). Aerodynamic performance analysis of an airborne wind turbine system with NREL Phase IV rotor. Energy Conversion and Management 134, 278-289.

Shahizare, B., Nik-Ghazali, N, Chong, W, Tabatabaeikia, S., Izadyar, N., Esmaeilzadeh, A. (2016). Novel investigation of the different Omni-direction-guide-vane angles effects on the urban vertical axis wind turbine output power via threedimensional numerical simulation. Energy Conversion and Management 117, 206-217.

Shen, X., Yang, H., Chen, J., Zhu, X. Z. (2016). Aerodynamic shape optimization of non-straight small wind turbine blades. Energy Conversion and Management 119, 266-278.
Sun, X., Zhu, J, Li, Z. and Sun, G. (2021). Rotation improvement of vertical axis wind turbine by offsetting pitching angles and changing blade numbers. Energy 215, 119177.

Wekesa, W.D, Wang, C, Wei, Y, Danao, L.A. (2014). Influence of operating conditions on unsteady wind performance of vertical axis wind turbines operating within a fluctuating free-stream: A numerical study. Journal of Wind Engineering 135, 76-89.

Wekesa, W.D, Wang, C.,Wei, Y, Kamau, J.N. and Danao, L.A. (2015). A numerical analysis of unsteady inflow wind for site specific vertical axis wind turbine: A case study for Marsabit and Garissa in Kenya. Renewable Energy 76, 648-661.

Wong, H.K., Chong, W.T, Poh, S.C., Shiah, Y.C., Sukiman, L. and Wang, C.T (2018). 3D CFD simulation and parametric study of a flat plate deflector for vertical axis wind turbine. Renewable energy 129, 32-55.

(C) 2021. This article is an open access article distributed under the terms and conditions of the Creative Commons AttributionShareAlike 4.0 (CC BY-SA) International License (http://creativecommons.org/licenses/by-sa/4.0/) 